Revista de Derecho YACHAQ N. ${ }^{\circ} 12$

Centro de Investigación de los Estudiantes de Derecho (CIED)

Universidad Nacional de San Antonio Abad del Cusco

ISSN: 2707-1197 (en linea)

ISSN: 1817-597X (impresa)

Fecha de recepción: 24/10/2020

Fecha de aceptación: 08/01/2021

[pp. 179-190]

\title{
Samuel, un juez penitente al servicio de Mefistófeles, lustitia y Verité
}

\author{
Samuel, a penitent judge in the service \\ of Mephistopheles, lusitia and Verité
}

\author{
Alejandro Ramírez Vélez ${ }^{[*]}$
}

\begin{abstract}
Resumen: en este ensayo se aborda la relación que existe entre el rol del juez y el cine, a partir de un cortometraje realizado por Martín Agudelo Ramírez titulado Un guardián frente al espejo. Se procurará esbozar las dificultades a las que se enfrenta un juez en la dirección de un proceso que está mediado por la constante disyuntiva entre verdad, la justicia y el derecho. Para tal efecto se analizan textos filosóficos y películas que tienen relación con el saber jurídico. Se muestra cómo, a partir del principio del juez tropos y de la reflexión en torno a la moral y al sentimiento de justicia, los juristas pueden afrontar y despejar algunos obstáculos epistemológicos y pragmáticos presentes en la labor de las autoridades jurisdiccionales. Igualmente, se contrasta la situación de lo que se ha considerado como «decisiones justas» frente a las dificultades que surgen del arraigo al planteamiento normativista del Estado decimonónico.
\end{abstract}

Palabras clave: juez tropos, derecho procesal, cine, justicia, verdad.

Abstract: this essay addresses the relationship between the role of the judge and the cinema from a film made by Martín Agudelo Ramírez entitled $A$ guardian before the mirror. An attempt will be made to outline the difficulties faced by a judge in the conduct of a process that is mediated by the constant choice between truth, justice and law, for which philosophical texts and films related to legal knowledge are analyzed. It shows how, starting from the principle of the judge tropos and from the reflection on morality and the feeling of justice, jurists can face and clear some epistemological and pragmatic obstacles present in the work of the jurisdictional authorities. Likewise, the situation of what has been considered «just decisions» is contrasted with the difficulties that arise from taking root in the normative approach of the nineteenth-century State.

Key words: judge tropos, procedural law, movies, justice, truth.

[*] Estudiante del programa de Derecho de la Universidad Pontificia Bolivariana, sede Medellín, Colombia. Correo electrónico: alejandro.ramirezve @upb.edu.co 


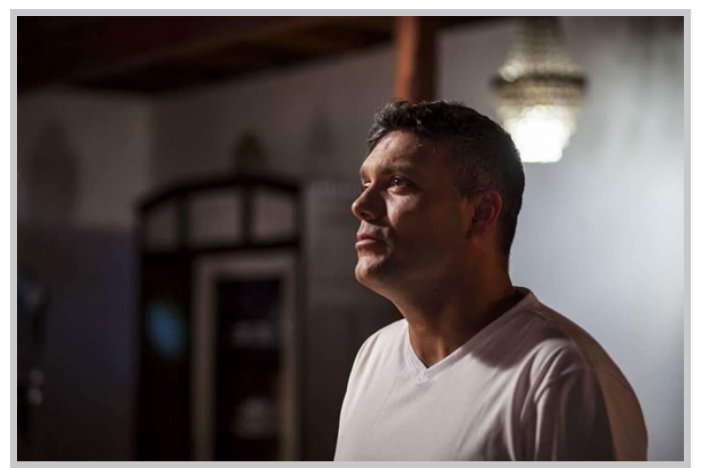

Imagen 1. Samuel, personaje principal del cortometraje Un guardián ante el espejo de Martín Agudelo Ramírez. Interpretado por Felipe Giraldo.

Imagínese, tan solo por un instante, que los palacios de justicia son salas consagradas al séptimo arte. De antemano, se ha de decir que este pensamiento no es descabellado. Los abogados, en el desarrollo de un proceso, hacen las veces de directores de un filme que proyectan a quien dirimirá un conflicto; y el juez actúa como el buen espectador, el experto en el cine, el sacerdote de negro que, oculto entre la penumbra de una sala, discierne qué sucede en la película que le están proyectando los letrados. El propósito de este ejercicio imaginativo es traer a la luz un escenario sacado de la Divina Comedia del güelfo Dante Alighieri.

El 16 de febrero de 2017, en un cine de la ciudad de Medellín, Vizcaya para ser exactos, muchos amantes de las artes plásticas y del cine se congregaron como feligreses para ver un documental dirigido por Ralph Loop (2016), que versaba sobre un tema de gran interés, el mapa que Sandro Botticelli, el pintor de la Venus, hizo del abismo infernal descrito por los poemas dantescos. Pasados unos minutos del documental, el público se percató de que el infierno se estaba haciendo palpable en aquel teatro. El humo salía en cantidades alarmantes desde la cámara del proyector y se observaban las sombras de las llamas que estaban consumiendo la cinta en la pantalla. Irónicamente el infierno se hizo presente mientras se proyectaba un documental sobre el infierno. Ese público vivió en carne propia, sin saberlo, aquello que viven muchos jueces en el ejercicio de la profesión jurídica. Presenciando una película vieron como los miedos, el calor, la frustración, el desespero y la confusión tomaban la batuta ante los espectadores anónimos. La única diferencia entre los espectadores del documental de Loop y los jueces, es que los primeros podían escapar del infierno que se cierne sobre la tierra, mientras que, a los segundos, por más que lo intenten, solo les queda buscar consuelo en la Nuda Veritas y en la dama de los ojos vendados.

En las siguientes páginas se dará cuenta de la labor de los letrados, en especial del juez, en relación con la verdad y la justicia. Se mostrará cómo el ministerio jurídico ha sido, como lo fue Fausto, un fatídico y cansado luchador que constantemente claudica en su cruzada por la verdad y la justicia; cede ante el embate de Mefistófeles, el exceso ritual manifiesto y la perpetua miopía que le impide al letrado ver más allá del derecho puesto, del derecho creado por el hombre. Todo lo anterior se hará tomando como punto de partida la relación existente entre derecho y cine; y el cortometraje con guion del magistrado Martín Agudelo Ramírez, Un guardián ante el espejo.

Así las cosas, el presente ensayo se sirve de un acervo investigativo para observar diferentes matices referentes a las trabas que el derecho realiza a la justicia y a la verdad. Aunque reciba una fuerte crítica, se ha de hacer un «spoiler» sobre este ensayo; es muy posible que no se llegue a una solución absoluta e indiscutida. Pero ello no ha de ser un obstáculo que impida escribir para procurar recobrar el valor que antaño tenían los jurisconsultos de la ciudad eterna, Roma. El lector deberá sumergirse en la mente de un guardián fragmentado por el trajín de una perpetua batalla para intentar descifrar qué es del juez que observa la realidad de las sociedades contemporáneas y en vez de cerrar los ojos, le sostiene la mirada. Aunque no se llegue a una solución, es necesario derramar el conocimiento con valentía, porque como lo escribía Publio Virgilio 
Marón (19 a. C., 2019), en la Eneida, «fortuna audentis iuvat» ${ }^{[1]}$ (p. 284).

El profesor Agudelo[2], en una de sus clases, realizó una pregunta que hizo tambalear cada uno de los pilares sobre los que se ha construido mi educación jurídica. Al charlar sobre Un guardián ante el espejo, película de su autoría, unos cuantos alumnos le preguntaron si dicho cortometraje tenía algo de autobiográfico, si él se veía a sí mismo como a Samuel, juez protagonista de la pieza analizada. El profesor Agudelo hizo su típica mirada de incredulidad, aquella llena de perspicacia que caracteriza a los profesores al escuchar una respuesta sumamente incorrecta. En lugar de contestar, realizó una contrapregunta: «Jóvenes, hay mucho de Samuel en mí, pero eso no es lo importante. Lo importante, estudiantes, es que se pregunten cuánto hay de Samuel en cada uno de ustedes». ¿Cuánto de Samuel hay en mí? Mi respuesta es que yo soy un Samuel más. Un Ícaro entre muchos que cree que está por llegar a la cúspide del orden humano, pero que desciende, incinerado, por volar muy cerca del sol.

El cortometraje, codirigido por Andrés Ricaurte y Martín Agudelo, lleva a su espectador cerca del sol, por ello genera un sinfín de preguntas a quien lo analiza, algunas de tamaña trascendencia para el ejercicio del derecho como las siguientes: ¿Cuánto de Samuel tienen todos los jueces? E incluso se puede llevar más allá para preguntarse: ¿Acaso todos los letrados del derecho tienen algo de Samuel?
La respuesta ha de ser, sin duda alguna, un rotundo sí. La grandeza del filme de Agudelo es que logró captar en cámara el tormento al que se somete todo hombre pensante dedicado al ejercicio del derecho. Hay una pugna entre la comodidad de las ritualidades, de las costumbres y de las leyes que hacen parte de un sistema jurídico debidamente estructurado y la búsqueda de una luz propia que solo tiene Verité ${ }^{[3]}$. Es decir, hay una configuración binaria que existe dentro de los hombres que debe ser entendida a la manera de Luhmann (19841993/2018), el cual da cuenta de una rivalidad biconceptual dentro del espíritu del hombre letrado ¿Es justo o injusto? ¿Es legal o ilegal? ¿Es derecho o no es derecho? ¿Es verdadero o no es verdadero?

Para aquellos lectores que no hayan visto el cortometraje, se ha de explicar en unas breves líneas quién es Samuel y cuál es su dilema. Samuel desempeña un cargo de juzgado, es un hombre riguroso y sumamente preocupado por las formas, que no siente miedo al momento de fallar y que ha entregado cada segundo de su existencia a complacer a aquella dama de bronce que tiene la cara tan fatigada. Un día este funcionario se encuentra en una situación de fácil resolución de cara al derecho, pero que moralmente lo sitúa en una fatal encrucijada. Una anciana acude al tribunal para que sus derechos sean tutelados. En el marco del proceso no se practica la prueba reina que serviría de soporte a la favorabilidad de la tutela soli-

[1] El verso de la Eneida traducido, literalmente, dice: «la fortuna favorece a los audaces».

[2] Martín Agudelo Ramírez es un abogado y teólogo graduado de la Universidad Autónoma Latinoamericana de Medellín y de la Universidad Pontificia Bolivariana de Medellín, respectivamente. Actualmente se desempeña como magistrado del Tribunal Superior del Distrito Judicial de Medellín y como profesor catedrático de derecho procesal general I y II en la Universidad Pontificia Bolivariana de Medellín. Ha incursionado en el cine realizando algunos filmes entre los que se destacan: Un camino para Tomás (2019), Un guardián ante el espejo (2018) y Tríptico de una dama extraviada (2017).

[3] Verité es la denominación francesa de Veritas, diosa romana hija de Virtus, diosa de la virtud, y de Saturno, dios del tiempo. En este ensayo nos referiremos a Veritas como Verité por el cuadro Édouard Debat-Ponsan de 1898. El cuadro tiene dos posibles nombres: Nec mergitur (Que no salga) o La Vérité sortant du puits (La verdad saliendo del pozo). 
citada por la mencionada mujer. La mente del guardián de la ley se ve fraccionada en un verdadero dilema psicológico y deontológico. Se pregunta constantemente qué hubiera pasado si hubiera tomado la actitud de un juez tropos y cómo hubiera podido cambiar el curso del proceso con una prueba decretada de manera oficiosa. Su cónyuge lo abandona porque se ha ensimismado en las labores de guardián y ha perdido de vista todo tipo de deber y actitud conyugal. El juez que antes estaba acompañado, de quien él pensaba que era lustitia y de su cónyuge, ahora se encuentra solo.

La justicia, el derecho y lo verdadero son cosas diferentes. De tal diferencia surge, precisamente, la agonía de Samuel. Todo lo dicho suena sumamente idealizado, pero no puede perderse de vista que el derecho puede ser Mefistófeles y que lustitia puede no tener nada que ver con él. El derecho es forma, un conjunto de ritos que buscan proyectar seguridad y reafirmar contrafácticamente unas expectativas razonables de comportamiento que deben mantenerse a pesar de ser ignoradas por los coasociados destinatarios de las normas jurídicas. (Luhmann, 1984-1994/2018). Pero la justicia no es solo forma, no es solo el pudor de un código o del contenido de una ley, aparentemente, impoluta.

Siguiendo el hilo anterior, se puede afirmar, sin temor a errar, que Samuel es un guardián de la ley, no de la justicia ni de la verdad. Este guardián salió de la mente kafkiana y fue investido de la competencia necesaria para observar una puerta, la de la ley, por la que entraban o no entraban los súbditos del derecho. Este juez fue testigo de cómo aquella mujer que pretendía en nombre de la justicia se despojó de todo lo que ella era y tenía, para al fin ser una penitente en busca de las añoradas mieles de la verdad. Aunque Samuel era un guardián moralmente dubitativo, no le tembló la mano para sentenciar tal y como la verdad procesal había sido escrita. Como dice Joseph K en El proceso de Orson Welles (1962), al derecho «debía parecerle gracioso observar a una inocente pidiendo justicia». Ahora, al adentrarnos en Kafka se observa el perfecto parangón entre Samuel y el guardián de la ley.

«Ante la Ley hay un guardián que protege la puerta de entrada. Un hombre procedente del campo se acerca a él y le pide permiso para acceder a la Ley. Pero el guardián dice que en ese momento no le puede permitir la entrada. El hombre reflexiona y pregunta si podrá entrar más tarde.

-Es posible —responde el guardián-, pero no ahora». (Kafka, 1925/ 2013, p. 130).

La anciana esperó el acceso a la ley. Samuel le negó tal acceso por una carencia de pruebas materiales que acreditaran su pretensión. Ella, que logró que Samuel se rebele contra lo establecido y cambiara su manera de ver el mundo, hacía las veces de ese campesino ruso que llegaba esperanzado a las puertas de la ley buscando que se hiciera justicia para él y para su causa. Por otro lado, Samuel era aquel cosaco kafkiano, el guardián, aquel sacerdote vestido de negro que le impidió el paso a la justicia cerrándole las puertas de la ley ¿La decisión de Samuel pudo ser justa desde algún punto de vista? Claro que sí, desde el punto de vista formalista que Hobbes presenta en Leviatán y que la teoría absoluta del poder sigue a rajatabla. Para el autor inglés (1651/2015), la justicia se reduce a lo que es conforme o no es conforme con el derecho y la voluntad del legislador debidamente positivizada. Sucede que, aunque Samuel no creyera en dicha teoría, no es posible negar que la aplicó a cabalidad en el proceso, al igual que hace una gran cantidad de jueces.

El autor austrohúngaro estudió jurisprudencia en la Universidad Carolina de Praga, allí fue influenciado por uno de los abogados más destacados de su tiempo, Alfred Weber, quien le inculcó el estudio de Hobbes y de sociólogos como Saint-Simone, Durkheim y su hermano, Max Webber. Kafka, habiendo leído a Hobbes, logró describir la actitud de Samuel en los renglones del cuento «Ante la ley» de su libro El proceso: 
«—¿Qué quieres saber ahora? —pregunta el guardián-. Eres insaciable.

-Todos aspiran a la Ley — dice el hombre-. ¿Cómo es posible que durante tantos años sólo yo haya solicitado la entrada?

El guardián comprueba que el hombre ha llegado a su fin y, para que su débil oído pueda percibirlo, le grita:

- Ningún otro podía haber recibido permiso para entrar por esta puerta, pues esta entrada estaba reservada sólo para ti. Yo me voy ahora y cierro la puerta» (Kafka, 1925/2013, p. 130).

En el filme de Orson Welles (1962), tal como da cuenta el documental realizado por el ya mencionado magistrado Agudelo (2020), se muestra que no debe creerse en los togados que únicamente se sirven de libros y manuales de derecho, aquellos que parecen guardianes silenciosos y creen en las formas por las formas. Esos textos contienen la ley, considerada por Welles (1962) como una herramienta de control «pervertida y asquerosa», tal como un material pornográfico sumamente denigrante para la condición humana. (Agudelo, 2020).

Agudelo y Welles muestran una cara del sistema jurídico que hace que los feligreses de lustitia y Verité se desesperen a través de la vivencia de Joseph $\mathrm{K}$, el reo de El Proceso de Kafka, ya que este da cuenta de una estructura monumental que es despreciable por fuera como por dentro, que hace que los acusados y los inocentes se vean obnubilados por un lenguaje pulido por las élites jurídicas. Duncan Kennedy, miembro fundador de los Estudios Jurídicos Críticos en Estados Unidos de América escribió sobre las globalizaciones del derecho en su texto insignia: Las tres grandes globalizaciones del derecho y del pensamiento jurídico 1850-2000. Realiza un análisis a partir del ser del derecho. Afirma que hay unos centros intelectuales en los que se ha construido una cultura jurídica a partir de unas formas gramaticales que imperan en todo el pensamiento jurídico de regiones periféricas a tales centros.
Kennedy (1974/2015), argumenta que en ese centro se crea una «langue» (lengua), que se traduce en diferentes formas «parole» (palabra) propias de los diferentes sistemas jurídicos vigentes en los países periféricos.

Ahí está Samuel, en la parole creada en un país de periferia a la creación y producción jurídica, observando un infierno que se cierne sobre la tierra ¿Por qué un infierno? Porque la ley parece haber sido escrita por Mefistófeles, mítico personaje del Fausto de Von Goethe. En la película Faust. Eine deutsche Volkssage, dirigida por F.W. Murnau en 1926, Mefistófeles se presenta como un ser sumamente encantador, agradable, sensual, elegante y confiable. Mefistófeles parece más un ángel que un demonio. El largometraje de Murnau (1926), narra la historia de Fausto y del demonio Mefistófeles, el cual hace un pacto con un arcángel que tiene por objeto atraer al mal a Fausto, filósofo y alquimista, y arrebatarle lo divino que hay en él, tal como a la ley. El premio por ganar la apuesta es el dominio de su credo sobre toda la Tierra.

Al ver la película de Murnau se hace imposible no pensar en el derecho. Mefistófeles le dio a probar a los hombres de la ambrosía del poder, ello conllevó a que los jueces y abogados fueran encumbrados más allá de las nubes. Se les dotó de una labor cuasidivina que procuró llevar a buen término por y para el derecho. Dicho poder excluye la realidad individual, el espíritu poco o nada importa en un mundo oficinesco donde, parafraseando el guion del documental El proceso entre las trampas del poder (Agudelo, 2020), «el individuo se diluye mientras la racionalidad instrumental se empodera».

En un mundo donde el individuo no es objeto de los subsistemas sociales y jurídicos, sino que el objeto mismo es el derecho y la norma jurídica, se puede observar una presencia constante del absurdo de la vida humana mediante la prolongación de un infierno burocrático. El derecho, tal como lo da a entender 
el filósofo esloveno Slavoj Žižek, (1989/2001), se ofrece como un arma para el ejercicio de un poder domesticador y la justicia, como poder institucionalizado, su brazo ejecutor. No hay espacio para la justicia en tribunales donde sus guardianes son meros aplicadores de leyes.

El pensamiento de Žižek es bastante diciente a la luz del cortometraje Tríptico de una dama extraviada (Agudelo, 2017). Iustitia, es mostrada en dicho cortometraje como una mujer quebrada, una mujer de bronce que solo sirve para adornar los escritorios de los juristas. La Libertad le dice que si se une a ella su balanza se fijará en el lugar que le corresponde, le dice que junto a ella habrá equilibrio y acierto en sus decisiones. Siguiendo a Agudelo (2017), la libertad personificada le dice que junto a ella se pueden «sobreponer el poder mezquino que la degradó (...) poder nauseabundo que la paralizó». Nuevamente siguiendo a Žižek (1989/2001), la justicia desfiguró su dignidad al ser cooptada por el poder y al descender en el servilismo. La justicia consistió en el infierno burocrático, ella vendió el alma a Mefistófeles que se le presentó como Eunomia. Se ve, claramente que Samuel es, también, víctima de las sociedades de control de las que habla Foucault y que retratan Welles y Kafka:

«El proceso en los mundos de Kafka y Welles es producto de una sociedad cerrada de control. Que conduce al desarraigo y sacrificio de sus miembros. Una caricatura descarnada de un instrumento que aniquila al individuo y que impone un corrupto mundo burocrático, atrapado en trámites absurdos que se dilatan con el paso del tiempo. Es el mundo del papel acumulado (...)» (Agudelo, 2017).

Samuel tenía un deber que no cumplió. Es, también, victimario en la larga cadena tecnocrática que se desata a partir de los sistemas jurídicos de control contemporáneos. Samuel podía servirse de la Verité y enfrentar cara a cara a la quimera en la que se ha transformado el derecho, aquel derecho que deshumaniza al ser humano y lo volvió únicamente persona. El juez tiene herramientas para garantizar el debido proceso, entre las cuales destaco la más importante en este menester, ser juez tropos ¿Qué hubiera sido del proceso de la mujer anciana si Samuel hubiera propuesto pruebas de oficio que ayudaran a desvelar la verdad?

Como dice Agudelo (2007), es el juez director del proceso que ordena, impulsa, sanea y cumple con la inmediación procesal. Esta figura es una consecuencia lógica del principio de autoridad del juez, el cual ha permitido que los fines del proceso no sean «sacrificados por una comprensión dispositiva privatista del mismo». (Agudelo, 2007, p. 20). Se ha de observar que muchos sistemas jurídicos han adoptado una ideología dispositiva del proceso, los cuales inician mediante el impulso inicial de las partes, y tal como dice Agudelo (2007), a pesar de ello la ajenidad del juzgador, reclamada por los destinatarios de la norma particular y concreta que crea para poner fin al litigio, «no excluye el ejercicio de funciones propias de la dirección del proceso. Funciones que han de ser sistemáticamente concebidas con relación a los fines constitucionales». (p. 21). El desconocer un papel activo por parte del juez en el control y dirección del proceso comportaría un retroceso al Estado decimonónico, ello la teoría del legislador racional estaba en auge y se acrecentaba el escepticismo frente al juez.

Que el juez sea director y no solo observador, significa que vigila el buen devenir del proceso mediante tres figuras procesales, de las cuales solo haré mención: en primer lugar, despacho saneador, en segundo lugar, los poderes propios de la jurisdicción para prevenir cualquier conducta contraria a los principios y fines que rigen el proceso, y finalmente están los autos para mejor proveer cuando existan limitaciones de orden probatorio (Agudelo, 2007). En esta última figura se encuentra la solución para los distintos demonios que aquejan la mente de Samuel, ya que de esta figura dependía la posibilidad de decretar una prueba de oficio que contribuyera a una decisión cercana a la sensación de justicia. 
El retrato psicológico de Samuel está siendo cazado por la realidad cultural, que, en muchas ocasiones, tal como lo hicieron los presocráticos y los platónicos, ha tratado de recrear el orden cósmico a partir de un ejercicio de mímesis, imitación. Lo que observaron los distintos filósofos y pensadores del derecho fue que en el cosmos cada astro ocupa su lugar, y al hacerlo desarrolla una función específica para que todo se mantenga en un perfecto equilibrio. Es por lo anterior que se observó, en el desarrollo de las funciones sociales desde los defensores griegos hasta los abogados contemporáneos, que los letrados llevan a cabo una función que les ha sido asignada y que nadie más desempeña dentro de las diferentes civilizaciones. Precisamente por ello debían tener una serie de deberes que los hiciera comportarse de manera virtuosa de cara a los conocimientos, al lenguaje y las habilidades que adquieren en el transcurso de sus estudios y de su vida profesional.

¿Cuál es el rol de los letrados en derecho dentro de una sociedad? Repartir. El abogado y el magistrado reparten bienes y servicios mediante un ejercicio de justicia distributiva y justicia correctiva, tal como lo anota Aristóteles (siglo IV a. C., 2014), en su libro Ética para Nicómaco.

El texto de este ensayo no tiene por objeto ahondar en la definición de justicia para Aristóteles y para distintos filósofos del derecho, pero busca dar cuenta de que el griego logró percibir que los letrados debían tener unas pautas de conducta. Pautas que encuentran su razón de ser en que la justicia es la más grande de las virtudes. El letrado, entonces, es el hombre que más feliz puede hacer a su polis, a su urbe o a su patria. Una virtud es un buen hábito que sirve para elegir lo que es excelente o lo que haría el hombre prudente en cada caso concreto de acuerdo con el justo medio. Aristóteles, como afirma Bazán (2010), quería dar cuenta de que «(...) este hábito sólo se aprende mediante la prác- tica, lo que equivale a afirmar que se aprende a ser justo, practicando la justicia, siendo justo».

El letrado jamás está incrustado por sí mismo y en absoluta soledad dentro de la realidad social. La justicia «(...) no es una virtud absoluta y puramente individual; es relativa a un tercero, y esto es lo que hace que las más veces se la tenga por la más importante de las virtudes» (Bazán, 2010). Hay deberes impuestos a los jueces y abogados porque el hombre es un ser voluble, sometido a sus pasiones y a sus intereses ¿Cómo confiar la tarea de distribuir en justicia a la conciencia de hombres que puede usar su conocimiento cual sofistas para su propio beneficio? No, no es posible. El hombre inventó reglas del deber ser hipotéticas para regular «la existencia en coexistencia» (Solano, 2018), y el abogado no está exento de cumplir dicha serie de reglas y pautas propias de la profesión por el hecho de ser quien comparte techo, mesa y lecho con ellas.

Samuel, por consiguiente, debería ser el hombre más feliz en toda la faz del mundo. Pero sucede todo lo contrario. Samuel es un juez penitente al más puro estilo de La Caída de Albert Camus (1956/2013): «Todos somos casos excepcionales. iTodos queremos apelar a algo! Cada cual pretende ser inocente a toda costa, aunque para ello sea menester acusar al género humano y al cielo» (p. 24).

Entre aquellos que acusaron al género humano y al cielo se encuentra el homónimo del juez penitente de Un guardián ante el espejo, Samuel, profeta y último juez de Israel. Ya que este fue juez, sacerdote, guardián y ungió a Saúl y David como Reyes de Israel, algunos exegetas bíblicos han encumbrado su vida como una de las más importantes y relevantes del Antiguo Testamento. Es importante traer a colación al Samuel bíblico para hacer un pequeño y minucioso paralelo entre ambos jueces. La Biblia Hebraica ha descrito a los jueces como israelíes de gran sabiduría y pericia que desempeñaba tres tipos de funciones: en primer lugar, hacían de gobernador, en segundo 
lugar, hacían las veces de líder militar en tiempos de crisis, en tercer lugar, estaban investidos de lo que hoy entendemos como función jurisdiccional. El juez hebreo presidia las Bet $\operatorname{Din}^{[4]}$, para administrar justicia en el período anterior a la creación de una monarquía israelita ${ }^{[5]}$. Cada ciudad de Israel tendría un Bet Din, tal como lo indica Deuteronomio 16-18 (1971) «Jueces y oficiales pondrás en todas tus ciudades que Jehová tu Dios te dará en tus tribus, los cuales juzgarán al pueblo con justo juicio».

La historia del profeta Samuel converge con la historia del Samuel de Un guardián ante el espejo luego de que la desgracia se hiciera amante del pueblo de Israel. Elí, juez y sacerdote, había instruido a Samuel en las leyes de Israel y en la adoración a Yahvé como a un discípulo fiel y prudente. No obstante, sus hijos Hofni y Finees, ambos sacerdotes, encabezaron un ejército, de aproximadamente tres mil efectivos, a combatir a los filisteos en compañía del arca de la alianza, en esa contienda los israelíes sufrieron una derrota decisiva en la que la que ambos comandantes fueron abatidos y el arca tomada como botín de guerra. La viuda de Finees, antes de morir dijo: «Traspasada es la gloria de Israel; porque ha sido tomada el arca de Dios» (1 Samuel. 4:21). En este primer libro se cuenta que los sacerdotes y jueces anteriores a Samuel fueron increpados por su pueblo al ser percibidos como negligentes y ajenos al ministerio al que habían consagrado su vida.

Contrario sensu, el profeta Samuel es imagen de un juez íntegro: fiel a su misión, incondicional de Yahvé, honesto ante los hombres, es el depositario del favor divino y su palabra profética es sabia y certera. Una vez Samuel fue nombrado juez, su trabajo fue juzgar al pueblo de Israel como conjunto y a los servidores del cielo como un gran órgano interdependiente necesario para mantener la cohesión social y religiosa, Samuel «juzgaba a Israel en todos los lugares. Su punto de retorno era Ramá, donde tenía su hogar, y allí también juzgaba a Israel» (1 Samuel, 15-17).

Ambos jueces descubrieron que no bastaban los amuletos, en el caso bíblico el arca y en el caso del cortometraje la toga y el martillo, para que el derecho dejase de ser un fin en sí mismo y sirviera como un medio para alcanzar el fin por el cual fue creado como un objeto cultural del hombre. Duncan Kennedy (2015), postula una tesis en virtud de la cual afirma que entre 1900 y 1967 se extendió una conciencia jurídica en todo el mundo, es decir, un conjunto de categorías y conceptos que permitieron que muchos países receptores de la filosofía y teoría jurídica proveniente de Francia y Alemania, principalmente, crearan un gran conjunto de instituciones y figuras jurídicas inspiradas en el pensamiento social. Lo social era una ciencia, ideología y disciplina que se opuso al abuso de la deducción silogística, ya que se pensó que cada norma jurídica individualmente concebida es un medio para llegar a un fin, de igual manera, se entendió el derecho desde una mirada sociológica, el derecho se entendió como un medio para alcanzar un fin. ¿Qué fin? Lograr alcanzar el bienestar social a través del cumplimiento de unos objetivos propios del interés público que lograrían transformar el derecho luego de estudiar el «ser» de la sociedad.

La búsqueda por alcanzar el interés público, el bienestar de la comunidad, está presente en ambos personajes. El Samuel bíblico debió recuperar el arca mediante las armas para alcanzarlo, así como la credibilidad en la misma a través del buen juicio, mientras el Samuel de Un guardián ante el espejo debió juzgarse a sí

[4] Significa «casa de juicio», en hebreo.

[5] Thomas L. Thompson (2000), un teólogo y conocido miembro de la escuela de Copenhague, realizó una investigación sobre la historia temprana del pueblo de Israel. Afirma que los jueces bíblicos desempeñaron sus funciones alrededor del 1150 a. C. al 1025 a. C., es decir, hasta la elección del primer rey de Israel, Saúl. 
mismo para recuperar la integridad de la labor del togado, juzgar y dirimir conflictos de intereses calificados por conflictos de voluntades.

En la labor mencionada se puede ser inocente o culpable (Ossorio, 2017), el profeta es un inocente al servicio de su fe, el otro es un culpable que añora la inocencia perdida al traicionar a Verité en procura del formalismo normativista del pensamiento jurídico clásico. Así las cosas, ¿de qué son culpables Jean Baptiste Clamence ${ }^{[6]}$ y el Samuel que creó Martín Agudelo? ¿Cuál es el crimen que han cometido y del cual solo ellos se saben culpables? Ambos descubrieron que, después de creerse a sí mismos como guardianes de la justicia y de la igualdad, no han hecho nada más que complacerse a sí mismos teniéndose por buenos y justos. Este descubrimiento hace que la ensoñación pase a ser insomnio.

Samuel despierta una noche de un onírico invierno de su sentimiento de jurisconsulto. Encuentra en el arte su refugio, pues la Nuda Verité cobra vida para impregnarlo de un sentimiento tan arrollador que lo hizo percatarse de aquello que, sin temor a generalizar, falta a todos los jueces. Se observa en el cortometraje que Samuel debe armar un rompecabezas para sentirse pleno, solo falta una parte para completarlo. Falta la pieza más importante del puzle, la roja. Se dice que es roja porque de ese color se ve en el cortometraje, a diferencia de las demás, de igual manera, es la central y más importante del rompecabezas de su existencia ¿Qué puede significar? Esa pieza es muy sencilla, todos la conocían, pero la olvidaron. Se olvidó por la distinción que las teorías utilitarias positivistas hicieron entre derecho y moral. Filósofos de la talla de Bentham, Kelsen, Austin, Hart, Chiassoni y muchos otros propugnaron por la no necesaria conexión entre el derecho y la moral para evitar que el juez no fallara a su arbitrio en vez de fallar en derecho. Como lo dice Camus (1953/2013), en La Caída:
«Cubriendo de imprecaciones a hombres sin ley, que no pueden soportar ningún juicio. Porque, en efecto, no lo pueden soportar, mi muy querido amigo; ahí está toda la cuestión. El que se adhiere a una ley no teme el juicio, que vuelve a colocarlo en un orden en el que él cree. Pero el mayor de los tormentos humanos consiste en que lo juzguen a uno sin ley» (p. 36).

Estos filósofos del derecho, persiguiendo una causa sumamente acertada y racional, lograron impregnar en muchos sistemas jurídicos y ordenamientos jurídicos la ausencia total o casi total de la verdad real y la justicia al momento de fallar en un proceso. Haciendo que, como se observa en la serie II proceso creada por Alessandro Fabbri (2019), se llegue a negar la existencia de ambas a través de las palabras de Ruggero Barone, abogado defensor del caso central de la serie, quien dice a su cliente: «No, Linda, la verdad no existe. Es algo que se crea en el tribunal». Han creído que la verdad nunca ha existido, que es cosa que se inventa para nacer en un proceso, pero no para morir en él.

Pero la veracidad de esa afirmación solo puede ser cierta para un sector de la profesión. La pieza roja es la sensación de justicia de la que habla Ángel Ossorio y Gallardo (1919/2017), el juez ha de fallar persiguiendo siempre el sentimiento de justicia, buscando la verdad. Eso debe hacerse para preservar la fe y la confianza en la más sacra y admirable de las profesiones; la profesión que trabaja y se desvive por el orden y la justicia, el derecho. El pensamiento de Ossorio y Gallardo se puede resumir perfectamente con una cita de Fausto de von Goethe: «Nunca abandona la esperanza al hombre que piensa en miserias. Su mano ávida escarba la tierra en busca de tesoros, y se da por satisfecho si encuentra un vil gusano» (p. 73).

[6] Protagonista, y quizá único personaje, de La Caída de Albert Camús. 
Hay una conexión clara entre el derecho y las diferentes narraciones citadas. Kurt Vonnegut (Collins, 2018), esgrimía en su tesis doctoral de antropología, en la Universidad de Chicago, que cualquier historia podía ser graficada en un eje cartesiano. Este eje de Vonnegut, tiene un punto cúspide ubicado en el punto $(+Y)$ y un punto de fondo que se encuentra en el punto $(-Y)$; el primero es buena fortuna y el segundo es mala fortuna. El eje $X$, la línea horizontal que atraviesa el eje $Y$, tiene un punto de partida de la historia y un punto de entropía ${ }^{[7]}$. Así:

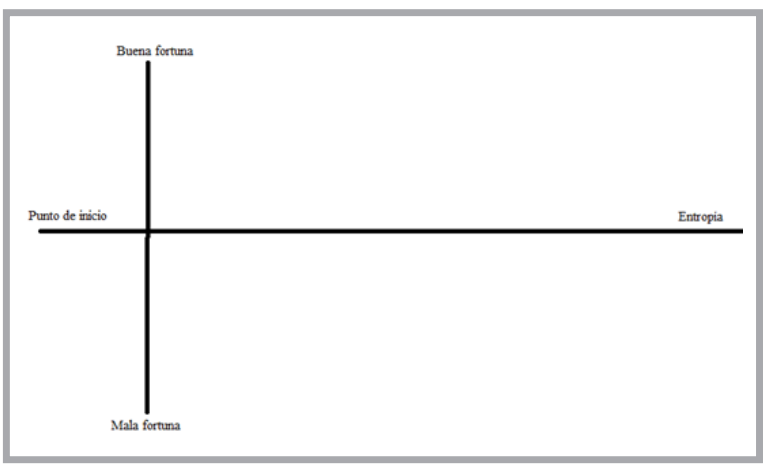

Figura 1. Elaboración propia a partir de la tesis doctoral en sociología de Kurt Vonnegut.

Entre esas líneas se puede aplicar y graficar cualesquier tropo narrativo; recaída, viaje del héroe, la vuelta a casa, la clásica historia de amor, la tragedia y la comedia. Pero si escondemos el punto de partida, hacemos que la buena y la mala fortuna sean conceptos inhóspitos y sumamente indeterminados y que el punto de entropía parpadee por todo el plano de manera azarosa mientras surgen distintas líneas de narración que comienzan en distintos puntos, se entrelazan entre sí y se cortan para luego continuar de forma desordenada y caótica, con lo cual tenemos la descripción perfecta de aquel infierno narrativo que se presenta al juez, y que él y nadie más tiene el deber de ordenar. Ahora, Samuel tiene una narración encuadrable en la tesis de Vonnegut, pero lo que lo perturba es el caos propio de una película de Béla Tarr (1994), que se le presenta proceso tras proceso. La labor del juez es así:

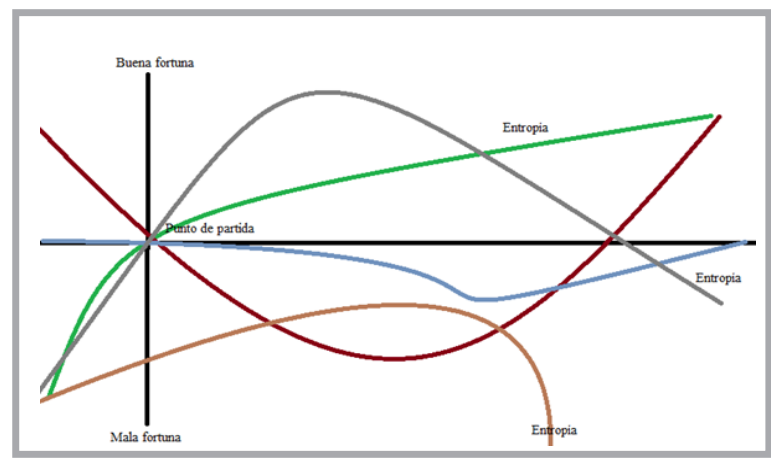

Figura 2. Elaboración propia a partir del Vídeo-ensayo sobre La Gran Belleza de Paolo Sorrentino y la cuestión de la narración de Maxim. (Maxím, 2016).

La labor del juez se centra en la interpretación del sinfín de variables que los letrados le proyectan, por eso se decía que la labor de los abogados es proyectarle una película en el juzgado. Debe mantener el orden social mediante la creación de normas jurídicas particulares y concretas dado el ejercicio ponderando de la ley. Sin embargo, tal como lo muestra Un guardián ante el espejo, el juez que quería dejar de ser hombre se ve sentado en el estrado de los acusados, y busca su solitaria absolución ante la verdad y la justicia.

El guardián, tarde o temprano, se enfrentará a situaciones que pondrán en jaque su constructo legal. $Y$ en ese momento de introspección psicológica es cuando el hombre se une con el juez y se concluye una única cosa: la autoridad jurisdiccional debe hacer más que solo dirigir, debe ser un sujeto activo que procure lograr los mínimos de derecho natural

[7] Vonnegut hace una especie de juego de palabras con la entropía, palabra que según la termodinámica puede significar el final último de todo. La entropía significa la tendencia a la perdida de orden en un sistema dado a que se ha alcanzado un grado de irreversibilidad luego de una serie de procedimientos en virtud de los cuales se transforma la energía. 
de los que habla H.LA. Hart en el Concepto del derecho (Hart, 1961/2012, p. 229). Independientemente de la existencia o inexistencia del derecho natural y de la justicia, no es posible pensar en efectividad del derecho sin aquellos mínimos que imperan en la realidad cultural que rodea a los letrados. Mínimos que son cruciales para mantener el sentimiento de legalidad que evita que los coasociados procedan a desenvainar las espadas y cargar los mosquetes en procura de la lucha por el derecho. El juez hace parte de la lapidaria sentencia de von Ihering (1872/2018): «El derecho es el trabajo sin descanso, y no solamente el trabajo de los poderes públicos, sino también el de todo el pueblo» (p. 50).

Finalmente, se ha de retomar una enseñanza que solo se comprende a través del cine. Samuel logró completar la pieza gracias a la apreciación del arte, vía para traer al mundo a lustitia y a Verité. El arte es el camino contemplativo para recuperar la vista y comprender que algunos fallos en derecho requieren, también, de una sensación de justicia que sea capaz de aplacar el infierno que se hace visible en cada sala de audiencias. También es aquello a lo que se aferra el letrado para no ceder ante los vericuetos de la ley por la ley y de las formas por las formas en el exceso ritual manifiesto.

Sin más que decir, en el presente ensayo se rindió cuenta de la insondable y sempiterna batalla por instrumentalizar el derecho de manera alarmante, pero el magistrado y cineasta Martín Agudelo nos demuestra que el arte es el reflejo de nuestras vergüenzas, pasiones y falencias como profesionales del derecho. Un guardián ante el espejo es, precisamente, el espejo que porta Verité al salir del pozo; razón por la que es tan sencillo vernos en los pies del juez penitente que rinde cuentas a la verdad. Solo queda por citar un adagio olvidado por muchos miembros del foro: Fiat iustitia ruat cælum ${ }^{[8]}$.

\section{REFERENCIAS}

\section{Bibliografía:}

Agudelo, J. M. (2007) El proceso jurisdiccional (Edición 1.). Editorial Comlibros

Aristóteles. (2014) Ética a Nicómaco (Traducción de Calvo, J. L.). Alianza Editorial. (Originalmente escrita en el siglo IV a. C.).

Bazán, C. (enero de 2005). Apuntes sobre la justicia en la Ética para Nicómaco. Aristóteles para juristas. lus et veritas, Volumen 17, 485-494. https://www.researchgate. net/publication/341358491_Apuntes_sobre_la_justicia_en_la_Etica_a_Nicomaco_ Aristoteles_para_juristas

Camus, A. (2012) La caída (traducción de De Lope, M.). Alianza Editorial. (Originalmente publicado en 1963).

Foucault, M. (2010) Las palabras y las cosas: Una arqueología de las ciencias humanas (Traducción de Frost, E, C. Edición 2). Editorial Siglo XXI. (Originalmente publicado en 1966).

Goethe, J. W. (2018) Fausto (Traducción de Cortés, H. Volumen 1. Edición 1.). Editorial Galaxia Gutenberg. (Originalmente publicado en 1808-1832).

Hart, H.L.A. (2012) El concepto del derecho (Traducción de Carrió, G. Edición 3). Editorial Abeledo Perrot. (Originalmente publicado en 1961).

Hobbes, T. (2005) Leviatán, o La materia, forma y poder de un estado eclesiástico y civil (Traducción de Sánchez, M.). Editorial Fondo de Cultura Económica y Social. (Originalmente publicado en 1651).

[8] Frase atribuida a Lucius Calpurnius Piso Caesoninus, cónsul romano en el 58 a. C., por Séneca en su obra De la Cólera, Libro I, Capítulo XVIII. Traduce literalmente: Que se haga justicia, aunque se desmorone la bóveda de los cielos. 
Ihering, R. V. (2018) La lucha por el derecho (Traducción de Lloredo, L.). Editorial Dykinson. (Originalmente publicado en 1872).

Kakfa, F. (2013) El proceso (Traducción de Sáenz, M.). Alianza Editorial. (Originalmente publicado en 1925).

Kennedy, D. (2015) Tres globalizaciones del derecho y del pensamiento jurídico 18502000 (Traducción de). Editorial Universidad Externado de Colombia. (Originalmente publicado en 1974).

Luhmann. N. (2018) La unidad del sistema jurídico. Escritos preparatorios para el derecho de la sociedad (Traducción de Newmark, H. F.). Editorial Universidad Externado de Colombia. (Originalmente publicado de 1984 a 1993).

Ossorio, A. (2017) El alma de la toga (Edición 1) Grupo Editorial Ibáñez. (Originalmente publicado en 1919).

Solano, H, R. (2018) Introducción al Estudio del derecho (Edición 1) Editorial Universidad Pontificia Bolivariana.

Thompson, T. (2000). Early History of the Israelite People: From the Written \& Archaeological Sources. [ Historia temprana del pueblo israelita: Fuentes escritas y arqueológicas]. Editorial E. J. Brill.

Virgilio. P, M. (2019) Eneida (Traducción de De Echave-Sustaeta). Editorial Gredos. (Originalmente publicado en 19 a. C.).

Žižek, S. (2001) El sublime objeto de la ideología (Traducción de Vericat, I. Edición 1). Editorial Siglo XXI (Originalmente publicado en 1989).

\section{Filmografía:}

Agudelo, J. M. (Director). (2017). Tríptico de una dama extraviada [Cortometraje]. Ramos, L., Salcedo, S., Rondón, J., Betancur, D. Betancur. https://www.youtube. $\mathrm{com} /$ watch? $\mathrm{v}=\mathrm{tz} Y a V O X q D 9 \mathrm{E}$

Agudelo, J. M. (Director). (2020). El proceso entre las trampas del poder [Documental]. Producción propia del director.

Eva Collins Alonso (2018). Kurt Vonnegut, Shape of Stories [Video]. Youtube. https://www. youtube.com/watch? $v=$ GOGru_4z1Vc

Fabbri, Alessandro. (2014) II Processo [El proceso]. [Serie]. Netflix: https://www.netflix. com/co/title/81221302

Loop, Rlph. (Director). (2016). Botticcelli inferno [Documental]. TV Plus Productions Germany; Medea Film; Irene Höfer; Nexo Digital.

Maxim (2016). La Gran Belleza - ¿Qué es narrar? [Video]. Youtube. https://www. youtube.com/watch? $\mathrm{v}=\mathrm{GBnPHMB}$ d_E\&list $=$ FLhMT9iam7WAF_bFcapLVdw\&index $=562$.

Ricaurte, A. \& Agudelo, M. (Director). (2019). Un guardián ante el espejo [Cortometraje]. Punto 8 Audiovisual.

Tarr, B. (Director). (1994). Sátántangó [Filmación]. György Fehér; Joachim von Vietinghoff; Ruth Waldburger

Welles, G. O. (Director). (1962). El proceso [Filmación]. Paris-Europa Productions HisaFilm; Finanziaria Cinematográfica Italiana. 